\title{
Improving immunization capacity in Ethiopia through continuous quality improvement interventions: a prospective quasi-experimental study
}

Tsegahun Manyazewal ${ }^{1,6^{*}}$ D. Alemayehu Mekonnen ${ }^{1}$, Tesfa Demelew', Semegnew Mengestu', Yusuf Abdu', Dereje Mammo ${ }^{2}$, Workeabeba Abebe ${ }^{3,4}$, Belay Haffa ${ }^{3}$, Daniel Zenebe ${ }^{1}$, Bogale Worku ${ }^{3}$, Amir Aman ${ }^{5}$

and Setegn Tigabu'

\begin{abstract}
Background: Strong scientific evidence is needed to support low-income countries in building effective and sustainable immunization programs and proactively engaging in global vaccine development and implementation initiatives. This study aimed to implement and evaluate the effectiveness of system-wide continuous quality improvement (CQI) interventions to improve national immunization programme performance in Ethiopia.

Methods: The study used a prospective, quasi-experimental design with an interrupted time-series analysis to collect data from 781 government health sectors (556 healthcare facilities, 196 district health offices, and 29 zonal health departments) selected from developing and emerging regions in Ethiopia. Procedures included baseline quality assessment of immunization programme and services using structured checklists; immunization systems strengthening using onsite technical support, training, and supportive supervision interventions in a Plan-Do-CheckAct cycle over 12 months; and collection and analysis of data at baseline and at the 6th and 12th month of interventions using statistical process control and the $t$-test. Outcome measures were the coverage of the vaccines pentavalent 3, measles, Bacillus Calmette-Guérin vaccine (BCG), Pneumococcal Conjugate Vaccine $(\mathrm{PCV})$, as well as full vaccination status; while process measures were changes in human resources, planning, service delivery, logistics and supply, documentation, coordination and collaboration, and monitoring and evaluation. Analysis and interpretation of data adhered to SQUIRE 2.0 guidelines.

Results: Prior to the interventions, vaccination coverage was low and all seven process indicators had an aggregate score of below $50 \%$, with significant differences in performance at healthcare facility level between developing and emerging regions ( $P=0.0001$ ). Following the interventions, vaccination coverage improved significantly from $63.6 \%$ at baseline to $79.3 \%$ for pentavalent $(P=0.0001), 62.5$ to $72.8 \%$ for measles $(P=0.009), 62.4$ to $73.5 \%$ for $\mathrm{BCG}(P=0.0001)$, 65.3 to $81.0 \%$ for PCV $(P=0.02)$, and insignificantly from 56.2 to $74.2 \%$ for full vaccination. All seven process indicators scored above $75 \%$ in all regions, with no significant differences found in performance between developing and emerging regions.

(Continued on next page)
\end{abstract}

\footnotetext{
* Correspondence: tsegahunm@gmail.com

${ }^{1}$ Ethiopian Public Health Association, P.O. Box 7117, Addis Ababa, Ethiopia

${ }^{6}$ Center for Innovative Drug Development and Therapeutic Trials for Africa (CDT-Africa), College of Health Sciences, Addis Ababa University, P.O. Box 9086, Addis Ababa, Ethiopia

Full list of author information is available at the end of the article
}

(c) The Author(s). 2018 Open Access This article is distributed under the terms of the Creative Commons Attribution 4.0 International License (http://creativecommons.org/licenses/by/4.0/), which permits unrestricted use, distribution, and reproduction in any medium, provided you give appropriate credit to the original author(s) and the source, provide a link to the Creative Commons license, and indicate if changes were made. The Creative Commons Public Domain Dedication waiver (http://creativecommons.org/publicdomain/zero/1.0/) applies to the data made available in this article, unless otherwise stated. 


\begin{abstract}
(Continued from previous page)
Conclusions: The CQI interventions improved immunization capacity and vaccination coverage in Ethiopia, where the unstable transmission patterns and intensity of infectious diseases necessitate for a state of readiness of the health system at all times. The approach was found to empower zone, district, and facility-level health sectors to exercise accountability and share ownership of immunization outcomes. While universal approaches can improve routine immunization, local innovative interventions that target local problems and dynamics are also necessary to achieve optimal coverage.
\end{abstract}

Keywords: Immunization, Continuous quality improvement, Vaccination, Expanded program on immunization, Ethiopia

\section{Background}

Vaccination has greatly lowered the burden of infectious diseases since the start of the Expanded Program on Immunization (EPI) by the World Health Organization (WHO) in 1974, reducing mortality, morbidity, and saving resources [1-4]. Vaccine innovations have been cultivated to tackle emerging and re-emerging diseases [5, 6] and combat antimicrobial resistance [7]. However, regardless of the rapidly changing immunization landscape, immunization programmes in resource limited countries still lag in bringing universal access of all relevant vaccines to all at-risk groups [8-10].

Ethiopia is among the countries adversely experiencing repeated epidemics and outbreaks of vaccine-preventable diseases, despite strong government-led efforts to combat this. A large proportion of vulnerable infants and children in Ethiopia are facing vaccine-preventable deaths, especially in communities that are hard-to-reach, poor, and sparsely populated. The deaths are mainly due to diarrheal diseases (18\%) and pneumonia (18\%) [11]. These deaths are intrinsically linked to a lack of timely, evidence-based interventions, which are more complex to deal with. Scientific literature in Ethiopia has affirmed that regional disparities [11, 12], administrative barriers [13], poor reporting [14], and a lack of skilled human resources [15] are serious challenges for the nation's immunization programme. In 2013, in light of such challenges, the Ethiopian Federal Ministry of Health (FMoH) initiated a national routine immunization improvement plan, which was a two-year (2014-2015) plan intended to improve national routine immunization programme performance and ensure equity of coverage among different populations [11]. In 2015, the FMoH developed a comprehensive multi-year plan of action, which covers the fiscal years 2016-2020, to expand the former plan and standardize entry of new vaccines into the country [16]. Ethiopia's individual and collective efforts with partners have resulted in some positives for the overall immunization system, including improved immunization coverage and accessibility of some new vaccines. However, these efforts have not been integrated and cultivated by locally appropriate quality improvement systems capable of achieving targets in the national immunization plan. National immunization activities are monitored using casual supervisory visits with less autonomy and opportunities given to district health bureaus to resolve bottlenecks onsite. The current national immunization plan requires new intervention mechanisms that would nurture the capacity and responsiveness of lower-level governments to own immunization programmes and mobilize the community to share responsibilities.

This study hypothesized that employing continuous quality improvement (CQI) interventions to assess, improve, and continuously follow-up immunization programme and services is an effective and sustainable approach to achieve Ethiopia's national immunization improvement plan. CQI is an iterative procedure of planning to improve a process, plan implementation, analyse and compare results, and take corrective actions [17]. Today's healthcare organizations are rapidly expanding CQI interventions worldwide to foster quality and sustainability of healthcare programmes and services [18-21].

The conceptual framework of the study is summarized in Fig. 1. The framework is designed based on the complete system of CQI in a Plan-Do-Check-Act (PDCA) cycle and the major areas of improvement of the Ethiopian routine immunization improvement plan [11]. The PDCA is a repetitive four-step management model for the control and continual improvement of processes and services [22]. Thus, this study aimed to implement and evaluate the effectiveness of system-wide CQI interventions to improve national immunization programme performance in Ethiopia.

\section{Methods \\ Context}

The study was performed in Ethiopia, where cases of vaccine-preventable diseases continue to exist [23]. The country is a federal state comprising nine regional states and two chartered cities. According to their level of economic and social development, the nine regional states are classified as developing and emerging regions. The former includes Amhara, Harari, Oromia, the Southern Nations, Nationalities and Peoples' Region (SNNPR), and Tigray, while the later includes Afar, Somali, Benishangul-Gumuz, and Gambella [24]. Compared with 


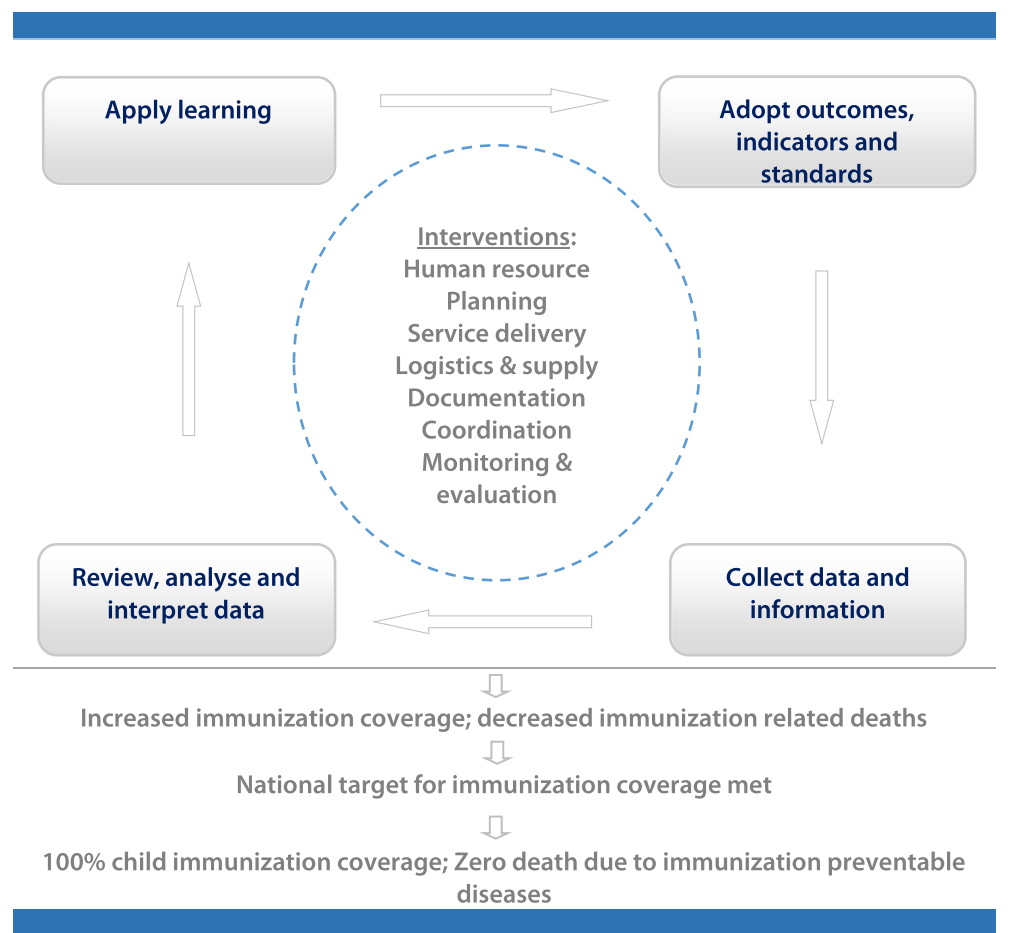

Fig. 1 Conceptual framework of the study design based on the complete system of CQI in a PDCA cycle. CQI: Continuous quality improvement; PDCA: Plan-Do-Check-Act

the developing regions, the emerging regions have a predominance of pastoral and agropastoral livelihoods with limited access to infrastructure and public services. The emerging regions lag behind in development, poverty reduction, and private investment [25]. The overall 11 administrative states are subdivided into 68 administrative zones and 817 districts, and the health system is structured accordingly in a top-down hierarchy [26].

In response to the FMoH's call for collaboration on the national routine immunization improvement plan, a consortium of three civil society organizations, namely, the Ethiopian Public Health Association, Ethiopian Medical Association, and Ethiopian Pediatrics Society, has worked since 2014 with the FMoH and Gavi, the Vaccine Alliance to design an innovative project on immunization. The goal of the consortium's project, entitled "Integrated approach to Empower Healthcare facilities on Immunization (IEHI)" was to ensure implementation and management of the best immunization services by public healthcare workers and their coordinators, which would have a sustainable and strong impact on immunization capacity in Ethiopia. The current study encloses the IEHI project, reinforcing scientific and evidence-based practices to improve immunization programmes in the country.

The target institutions of the study were zonal health departments, district health offices, and healthcare facilities in Ethiopia. The selection of the study sites was based on stratified multi-stage sampling. The nine regional states were stratified into two groups based on their formal level of economic and social development: developing regions $(n=5)$ and emerging regions $(n=4)$. Three regions were randomly selected from each group, making a total of six regions. From each of the six regions, all zonal health departments, district health offices, and local healthcare facilities were identified and checked individually adhering to certain criteria. The criteria included availability of immunization programme or services at the time of site selection; willingness of the site to enrol in the study and carry out ongoing interventions; and the site not already receiving technical support from other non-governmental EPI implementing partners.

The target participants of the study were EPI experts who manage and coordinate immunization programmes at zone and district levels, and healthcare workers who provide immunization services at healthcare facility and community levels. A participant was considered eligible if he/she was a full-time employee at the study site responsible for EPI programmes or services and was willing to give consent to participate. With this, 225 EPI experts who manage and coordinate immunization programmes at zone and district levels, and 556 healthcare workers who provide immunization services at 
healthcare facility and community levels were involved. Fifteen independent EPI consultants and three supervisors provided onsite technical support and supportive supervision (SS) visits. The independent consultants had a minimum of a master's degree in a health-related field of study and ample experience in managing, supervising, and implementing immunization programmes and services. The consultants were trained for five days by the investigators before being involved in the study. The target beneficiaries were all children in the immunization age group in the six selected regions.

\section{Interventions}

The study used a prospective, quasi-experimental design with an interrupted time-series applied in two phases. Phase I involved conducting a baseline assessment of study sites to serve as a benchmark for interventions. The baseline assessment was conducted over three months from October to December 2015 through onsite observations, preliminary interviews, and a review of facility data. The observations comprised inspecting availability and adequacy of immunization-related supplies, equipment, and immunization room setup. The data review involved assessing immunization-related plans, reports, relevant documents, communications, and monitoring and evaluation records. The interview segment involved face-to-face interviews with EPI experts and immunization service provides in order to investigate local views and enhance the study teams' understanding of how immunization programmes and services are actually delivered, monitored, evaluated, and reported. The initial data were collected using three structured CQI checklists designed to extrapolate the current immunization issues and identify opportunities for improvement in line with the targets of Ethiopia's national routine immunization improvement plan. The tools were designed independently for healthcare facilities, district health offices, and zonal health departments. Cronbach's alpha was measured to confirm internal consistency of the data tools. Independent EPI consultants collected the data. The structure and contents of the data collection tools are explained below.

Phase II involved implementing CQI interventions in a health systems strengthening package, which included onsite technical support, training, and SS in a PDCA cycle based on pertinent needs identified in the baseline assessment and taking into account indicators of the national immunization improvement plan. Each site was informed of the baseline findings and discussions were held with the study site's head, immunization focal person, maternal and child health focal person, and immunization service providers, as they were available. Then, each site was informed to develop plans to fill gaps identified in the baseline assessment. Follow-up assignments of developing long- and short-term plans were given at each site to ensure gaps identified in the baseline assessment were filled.

The training package was designed as a result of the baseline report, which indicated a high shortage of skilled workforce in immunization programmes and services. The target was for each site to have at least two staff trained on immunization to have the capacity to effectively manage the immunization programme or deliver immunization services. Therefore, a total of 513 EPI managers and coordinators at study zones and districts received a 10-day immunization for mid-level managers (MLM) training. The MLM curriculum was a readily available course designed by the WHO and approved by the FMoH [27]. The WHO designed the curriculum to help mid-level immunization managers effectively deliver vaccines to their communities. The standard course modules are: cold chain, vaccines, and safe-injection equipment management; partnering with the community; immunization safety; supportive supervision; monitoring the immunization system; making a comprehensive annual national plan; the EPI coverage survey; and making disease surveillance work. Each MLM module is organized around a series of steps in which technical information is provided, followed by learning activities.

Similarly, a total of 2236 healthcare providers involved in immunization services at healthcare facility and community levels received a five-day Immunization in Practice (IIP) training using the WHO's IIP curriculum that was approved by the $\mathrm{FMoH}$ [28]. The standard IIP curriculum has ten modules and was designed for healthcare workers who deliver immunization services to children and women. The course modules are: EPI target diseases; EPI vaccines; the vaccine cold chain; ensuring safe injections; organizing immunization sessions; registering and assessing clients; preparing vaccines; giving immunizations; communicating with parents and involving communities; and monitoring immunization coverage.

Following the training, the 15 independent EPI consultants provided onsite technical support on a quarterly basis backed by frequent technical consultation phone calls. The technical support was given in all aspects of human resources, planning, service delivery, logistics and supply, documentation, coordination and collaboration, and monitoring and evaluation. The consultants worked closely with site immunization focal persons to solve bottlenecks and maximize performance and uninterrupted immunization services. Three supervisors regularly rechecked and monitored activities of the consultants to ensure the quality of interventions. Using the CQI checklists, immunization staff and the site's head 
met monthly to discuss tested changes and to plan new tests of changes. These interventions lasted 12 months from January to December 2016.

\section{Measures}

The effectiveness of the CQI interventions was measured in terms of 'process' and 'outcome' indicators. The process was measured based on seven parameters at healthcare facility level and six parameters at district and zone levels: human resources, planning, logistics and supply, service delivery (only for healthcare facilities), documentation, coordination and collaboration, and monitoring and evaluation. The parameters were derived from core indicators that the Ethiopian national immunization improvement plan targets to achieve. The seven parameters and their detailed components and scoring are described in Table 1.

The outcome measures were represented by the coverage of five vaccinations: pentavalent 3 , measles, Bacillus Calmette-Guérin (BCG), Pneumococcal Conjugate Vaccine (PCV), and full vaccination (fully immunized). The figures of baseline vaccination coverage of catchments were collected from immunization registers available at each zonal health department, district health office, and healthcare facility. Such data were captured every six months during CQI interventions to compare with the baseline and analyse changes due to interventions.

\section{Analysis}

Data were entered into EPI Info ${ }^{\mathrm{Tm}}$ version 3.5.1 (Centers for Diseases Control and Prevention, Atlanta, US) and transferred to Statistical Package for the Social Sciences (SPSS) version 22 (IBM Corp., Armonk, NY, US) for analysis. Analysis and interpretation of data adhered to SQUIRE 2.0 (Standards for Quality Improvement Reporting Excellence) guidelines [29] to ensure quality of data and methodology. Process measures were calculated numerically, where each element in the seven parameters had a value of one for a positive outcome or a value of zero for a negative or null outcome. Aggregating all scores of the seven process measures produced a composite variable score to indicate a study site's status of immunization programme or services. The aggregate score of a study site was then changed to a percentage and classified: a score of below 50\% was considered 'low', a score ranging between 50 and $75 \%$ was 'fair', and a score of above $75 \%$ was 'good'.

Descriptive characteristics were summarized using counts, means, and proportions. A region's cumulative score was calculated as the average score of the seven process measures of all zonal health departments, district health offices, and healthcare facilities in the region. A cumulative score of a developing or emerging region was calculated as the percentage mean score of the seven process measures of all zonal health departments, district health offices, and healthcare facilities in the developing or emerging regions. Descriptive characteristics of outcome measures followed a similar method but using percentages of vaccination coverage. Data were analysed numerically using statistical process control to determine changes due to interventions. A $t$-test analysis was carried out to describe whether there were changes in the coverage of outcome measures through time. The $t$-test for equality of means was also employed to check if there were changes in vaccinations at baseline and at 6th and 12th month of CQI interventions. The $P$ value of $<0.05$ was considered statistically significant.

\section{Ethical considerations}

The study protocol was approved by the Internal Scientific and Ethical Review Committee of the Ethiopian Public Health Association. Permission to undertake the study was obtained from the $\mathrm{FMoH}$ and the Afar, Amhara, Gambella, Oromia, SNNPR, and Somali regional health bureaus. Privacies of staff involved were sufficiently protected.

\section{Results}

The study included 783 government health sectors, comprising 558 local healthcare facilities, 196 district health offices, and 29 zonal health departments; this covers $64.5 \%$ of zonal and $36 \%$ of district health bureaus in the study regions. All sites were willing to participate. Figure 2 is a map of Ethiopia showing the various districts included in the study. Table 2 summarizes the type and distribution of study sites.

\section{Results of process measures}

The process measures were changes in human resources, planning, service delivery, logistics and supply, documentation, coordination and collaboration, and monitoring and evaluation.

In terms of human resources, there were immunization focal persons in $96.6 \%$ of the zonal health departments, $90.3 \%$ of the district health offices, and $92.4 \%$ of the healthcare facilities at the time of baseline assessment, which was considered excellent. This figure was consistent at the 6th and 12th month of interventions at the zonal level, and it improved to around $98 \%$ at both the district and healthcare facility levels. The focal persons had the role of managing and coordinating immunization programmes and services at each level. In contrast, $82.8 \%$ of zonal health departments, $91.8 \%$ of district health offices, and $83.1 \%$ of healthcare facilities lacked the required number of experts who have undergone the MLM or IIP training (see Table 3). The percentage of experts trained in MLM increased from 17.2 to $82.1 \%$ at the zonal level and from 8.2 to $74.7 \%$ at the district level, and experts trained 
Table 1 Process measures, their components and scores

\begin{tabular}{lll}
\hline Process measures & Components & Scores (point) \\
\hline 1. Human resources & $\begin{array}{l}\text { 1.1. Proportion of zone, district, and healthcare facilities (HFs) with a designated immunization } \\
\text { focal person }\end{array}$ & $\begin{array}{l}4 \text { at zone, district, } \\
\text { and HF }\end{array}$ \\
& $\begin{array}{l}\text { 1.2. Proportion of zone and district with at least 2 MLM-trained experts } \\
\text { 1.3. Proportion of HFs with at least } 2 \text { IP-trained experts }\end{array}$ \\
& $\begin{array}{l}\text { 1.4. Proportion of zone, district, and HFs with a designated cold chain officer } \\
\text { management }\end{array}$ \\
1.6. Proportion of HFs with an expert on user/preventive cold chain
\end{tabular}

2. Planning

3. Logistics and supply

4. Service Delivery

5. Documentation

6. Coordination and collaboration

7. Monitoring and evaluation
2.1. Proportion of zone, district, and HFs with Reaching Every Community (REC) microplan

2.2. Proportion of HFs with outreach/mobile service delivery plan

2.3. Proportion of HFs with outreach/mobile REC microplan (if available), posted on the wall

3.1. Proportion of zone, district, and HFs with an adequate fridge-tag 2

3.2. Proportion of zone, district, and HFs with refrigerator spare parts

3.3. Proportion of zone, district, and HFs with vaccine request and report forms

3.4. Proportion of zone, district, and HFs with EPI vaccine and injection materials stock ledger book

3.5. Proportion of zone, district, and HFs with inventory documents

3.6. Proportion of HFs with adequate cold box

3.7. Proportion of HFs with adequate vaccine carrier with foam pads

3.8. Proportion of HFs with adequate vaccine storage capacity

3.9. Proportion of HFs with adequate water/ice packs

3.10. Proportion of zone, district, and HFs with no stock running out in the last 3 months

3.11. Proportion of zone, district, and HFs with refrigerator temperature monitored twice daily using fridge-tag 2

3.12. Proportion of zone, district, and HFs with no expired vaccines in refrigerator, or acceptable Vaccine Vial Monitor

3.13. Proportion of zone, district, and HFs with procedures and actions for vaccines exposed to extreme temperatures

4.1. Proportion of HFs with immunization services available

4.2. Proportion of HFs with regular static immunization services delivered

4.3. Proportion of HFs with adequate outreach sites

4.4. Proportion of HFs with catchment area mapped for immunization

4.5. Proportion of HFs with separate and adequate rooms to deliver immunization services and store supplies

4.6. Proportion of HFs with all planned outreach sessions conducted

4.7. Proportion of HFs providing health education on immunization

4.8. Proportion of HFs with immunization services available under all their catchment health posts

5.1. Proportion of zone, district, and HFs with electronic database for monitoring immunization and staff training

5.2. Proportion of zone, district, and HFs with standard operating procedures on immunization

5.3. Proportion of HFs with reports received from all catchment health posts and the reports are well documented

5.4. Proportion of HFs with tally sheets appropriately documented

5.5. Proportion of HFs with defaulter tracking list

5.6. Proportion of HFs with standard case definition for neonatal tetanus, measles, acute flaccid paralysis (AFP)

5.7. Proportion of HFs with an up-to-date under-one register

5.8. Proportion of zone, district, and HFs with up-to-date national immunization guidelines

6.1. Proportion of zone with established partners' forum

6.2. Proportion of zone with partners' forum meeting conducted as planned

6.3. Proportion of zone and district with EPI programme network

6.4. Proportion of district with established technical working group

6.5. Proportion of district with a technical working group meeting conducted in the last quarter

6.6. Proportion of HFs conducting a catchment area meeting in the last quarter

6.7. Proportion of HFs with established inter-facility linkage on immunization services

7.1. Proportion of zone, district, and HFs posting updated EPI monitoring chart

7.2. Proportion of HFs with vaccine logs

7.3. Proportion of HFs with vaccine and injection materials stock record book

7.4. Proportion of zone, district, and HFs conducting an internal review meeting on EPI in the last quarter

7.5. Proportion of zone, district, and HFs having a SS visit by government or partners in the last quarter

7.6. Proportion of zone, district, and HFs having a data quality check by the government or partners in the last quarter

7.7. Proportion of zone, district, and HFs with timeliness of monthly reports

7.8. Proportion of zone, district, and HFs with completeness of monthly reports
3 at HF, 2 at zone and district

13 at HF,9 at zone and district

8 at HF,

0 at zone and district

8 at HF,

3 at zone and district

4 at zone and district,

2 at HF

11 at HF,

8 at zone and district 
Table 1 Process measures, their components and scores (Continued)

\begin{tabular}{ll}
\hline Process measures & Components \\
\hline 7.9. Proportion of zone, district, and HFs with a functional performance monitoring team & Scores (point) \\
7.10. Proportion of zone and district with monitored vaccine wastage & 7.11. Proportion of HFs conducting SS of health posts in the last three months \\
7.12. Proportion of HFs supervising community immunization programme in the last three months
\end{tabular}

EPI: Expanded Program on Immunization; HF: Healthcare facility; MLM: Mid-level managers; SS: Supportive supervision

in IIP increased from 16.9 to $81.1 \%$ at the healthcare facility level after 12 months of interventions. This was due to training interventions being delivered to 513 MLM and 2236 IIP training participants. Consultations given to heads of study sites as part of onsite technical support resulted in a higher number of cold chain officers at each level (see Table 3). The average number of experts assigned for immunization at the zonal level was two at baseline, which was improved to three at the 6th month and four at the 12th month of interventions, with much improvement observed in Gambella, Oromia, and SNNPR. Similar improvements were recorded at the district level, except for Gambella, and at the healthcare facility level, except for Amhara.

Regarding planning, only $34.5 \%$ of zonal health departments, $45.9 \%$ of district health offices, and $27.6 \%$ of healthcare facilities had the Reaching Every Community (REC) microplan at baseline to enable them to map community locations and characteristics, and the resources required for routine immunization. After 12 months of technical support, REC microplans were prevalent at $71.4 \%$ of zonal health departments, $72.6 \%$ of district health offices, and $59.6 \%$ of healthcare facilities.

Availability of logistics, supplies, and equipment showed some improvement over time, while items such as refrigerator spare parts were still lacking in zonal health departments 12 months following the interventions (see Table 3). The overall level of logistics and supply at the zonal level showed some improvements, with much better results observed in Oromia and SSNPR.

The baseline analysis for documentation was poor: only $41.4 \%$ of zonal health departments, $30.1 \%$ of district health offices, and $12.5 \%$ of healthcare facilities were able to use the electronic database system for immunization. At the 12th month point of interventions, these figures improved to $67.9,40$, and $25.8 \%$, respectively. Similarly, only $24.1 \%$ of zonal health departments, $30.6 \%$ of district health offices, and $23.7 \%$ of healthcare

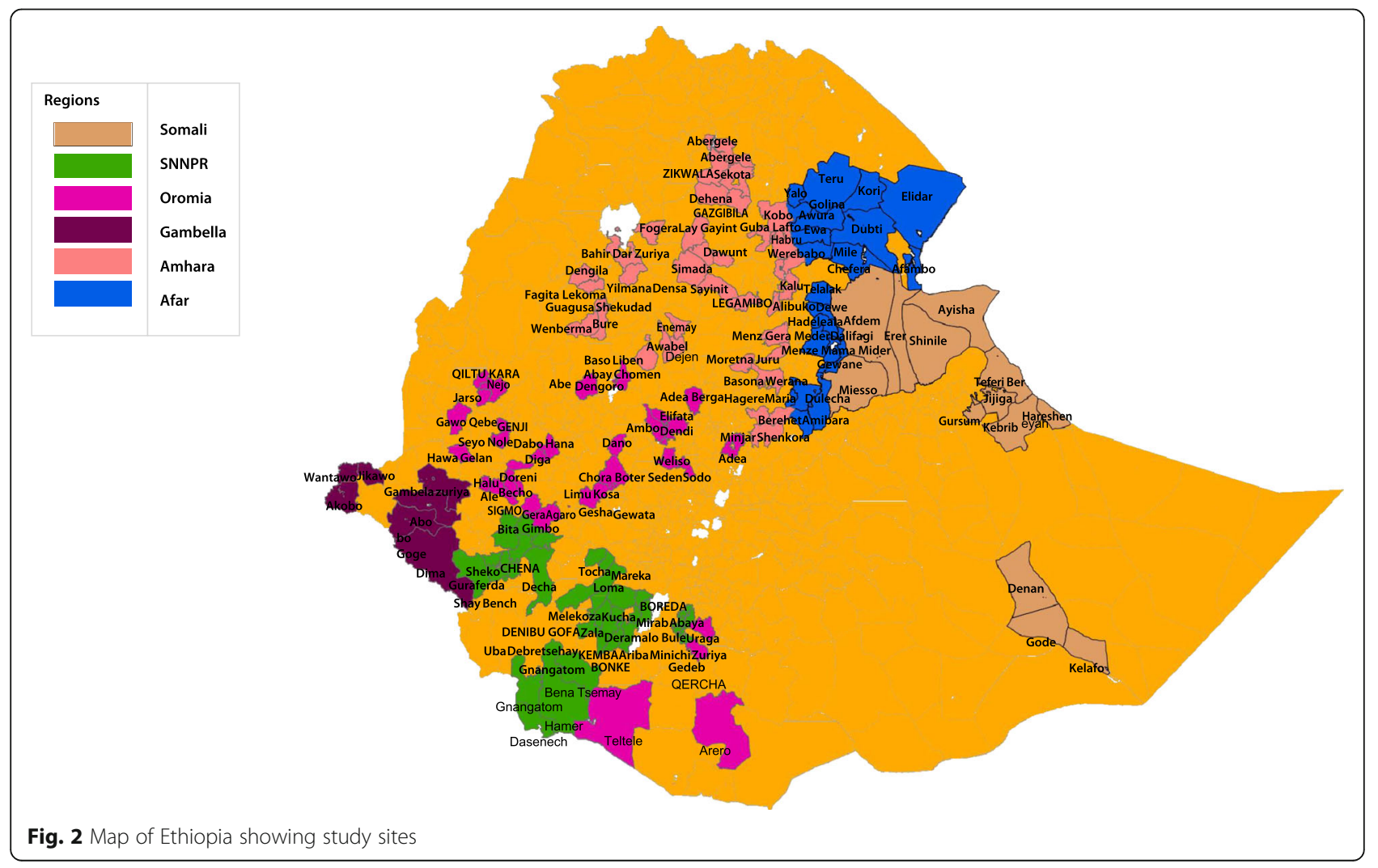


Table 2 Type and distribution of study sites

\begin{tabular}{cclll}
\hline Regions & $\begin{array}{l}\text { Zonal health } \\
\text { department }(f)\end{array}$ & $\begin{array}{l}\text { District health } \\
\text { office }(f)\end{array}$ & $\begin{array}{l}\text { Healthcare } \\
\text { facility }(f)\end{array}$ & $\begin{array}{l}\text { Total } \\
(f)\end{array}$ \\
\hline $\begin{array}{rlll}\text { Developing regions } \\
\text { Amhara }\end{array}$ & 8 & 42 & 146 & 196 \\
Oromia & 10 & 43 & 155 & 208 \\
SNNPR & 8 & 44 & 120 & 172 \\
Emerging regions & & & \\
Afar & NA & 26 & 56 & 82 \\
Gambella & 3 & 13 & 29 & 45 \\
Somali & NA & 28 & 50 & 78 \\
Total & 29 & 196 & 556 & 781 \\
\hline
\end{tabular}

NA: Not available; SNNPR: Southern nations, nationalities and Peoples' Region

facilities had standard operating procedures on immunization, which was improved to 67.9, 57.4, and $56.4 \%$, respectively (see Table 3). At baseline, up-to-date national immunization guidelines were available at $62.1 \%$ of zonal health departments, $35.2 \%$ of district health offices, and $34.4 \%$ of healthcare facilities, which was improved to $89.3,94.2$, and $88.6 \%$, respectively, after interventions that included distributing the guidelines from central health bureaus.

In terms of coordination and collaboration, at baseline, $14 \%$ of zonal health departments had an established partners' forum made up of governmental and non-governmental organizations that met every three months and discussed immunization issues in their catchment. Of these, $6.9 \%$ were able to conduct a partners' forum meeting as planned. This improved to $26.4 \%$ of zonal health departments having such forums, and $28.6 \%$ of these conducting a partners' forum meeting by the 12th month of interventions. Similarly, $30 \%$ of district health offices had an established immunization technical working group, of which $16.8 \%$ conducted a technical working group meeting in the last quarter. This was improved to $55.4 \%$ of district health offices having such a group, and $43.2 \%$ of them conducting a meeting after 12 months of interventions.

Regarding monitoring and evaluation, $62.1 \%$ of zonal health departments, $62.8 \%$ of district health offices, and $57.2 \%$ of healthcare facilities had an updated EPI monitoring chart. After the training and onsite technical support, this improved to $89.3,88.0$, and $84.1 \%$, respectively. Completeness of monthly reports was also improved from 65.5 to $89.3 \%$ at the zone level, 61.2 to $94.7 \%$ at the district level, and 58.1 to $81.5 \%$ at healthcare facility level after interventions. All regions were able to improve their monitoring and evaluation and data management activities, with the improvement significant in SNNPR and Oromia.

Analysing the baseline cumulative score of the six process indicators, the national immunization programme and services capacity was found to be low $(<50 \%)$ (see Table 4$)$. Comparing the six parameters within themselves, logistics and supply, as well as human resources had relatively better cumulative scores.

The regional average was computed for baseline process indicators, with Amhara (60.2\%) and Afar (51.2\%) scoring in the range of 50.0 to $75.0 \%$ (fair), while all other regions scoring below 50.0\%: Somalia (48.0\%), SNNPR (45.5\%), Oromia (36.7\%), and Gambella (34.9\%). There were significant differences in baseline process indicators among regions $(P<0.001)$. Baseline mean values were also compares between developing and emerging regions, with a significant difference found between the two in terms of process indicators at the healthcare facility level $(P=0.0001)$ but not at the district level $(P=0.715)$.

Analysing the cumulative score of the seven process indicators after interventions, the national capacity to deliver immunization programme and services was found to be high, with a score of above $75 \%$ which was a major increase from below $50 \%$ at baseline; these improvements were observed at the zone, district, and healthcare facility (see Fig. 3) levels. The regional average was computed and it was found that all regions improved their immunization programmes and services after interventions, yet there was a bigger improvement in Gambella and SNNPR both at the 6th and 12th month of interventions as compared to the other regions. Gambella, SNNPR, and Amhara scored 'good' at 6th months of interventions and the rest scored 'fair'. There was a declining trend in some regions from the 6th month to the 12th month of interventions.

\section{Results of outcome measures}

Pentavalent 3, measles, BCG, PCV, and full vaccination status were the outcome measures used to observe changes in immunization coverage. Comparing vaccination coverage from baseline to the 12th month of interventions, it improved significantly from 63.6 to $79.3 \%$ for pentavalent ( $P=0.0001), 62.5$ to $72.8 \%$ for measles $(P=0.009), 62.4$ to $73.5 \%$ for BCG $(P=0.0001), 65.3$ to $81.0 \%$ for PCV $(P=0.02)$, and insignificantly from 56.2 to $74.2 \%$ for full vaccination (see Table 5 ).

Tremendous changes were observed in the coverage of all five types of vaccinations in all six regions (see Fig. 4). Full vaccination in SNNPR at the 6th month of interventions and BCG vaccination in Gambella at baseline had exceptionally high values, which could be due to mass vaccination for disease-specific epidemics in these regions. In most regions, an independent $t$-test showed that there were significant changes in the percentage means of all five vaccination types from the baseline to the 12th month of interventions. 
Table 3 Percentage scores of process measures at baseline, and at the 6th and 12th month of interventions

\begin{tabular}{|c|c|c|c|c|c|c|c|c|c|}
\hline \multirow[t]{2}{*}{ Process measures } & \multicolumn{3}{|c|}{ Baseline (\%) } & \multicolumn{3}{|c|}{ After 6 months (\%) } & \multicolumn{3}{|c|}{ After 12 months (\%) } \\
\hline & Zone & Dist. & $\mathrm{HF}$ & Zone & Dist. & $\mathrm{HF}$ & Zone & Dist. & $\mathrm{HF}$ \\
\hline \multicolumn{10}{|l|}{ 1. Human resources } \\
\hline 1.1. A designated immunization focal person & 96.6 & 90.3 & 92.4 & 96.6 & 98.3 & 98.0 & 96.4 & 97.9 & 98.0 \\
\hline 1.2. At least $2 \mathrm{MLM}$-trained experts & 17.2 & 8.2 & NA & 86.2 & 61.4 & NA & 82.1 & 74.7 & NA \\
\hline 1.3. At least 2 IIP-trained experts & NA & NA & 16.9 & NA & NA & 85.4 & NA & NA & 81.1 \\
\hline 1.4. A designated cold chain officer & 58.6 & 43.9 & 32.1 & 79 & 70 & 43 & 82.1 & 67.4 & 51.6 \\
\hline 1.5. An expert/technician on mid-level cold chain management & 58.6 & 87.1 & NA & 79 & 62.4 & NA & 92.9 & 68.9 & NA \\
\hline 1.6. An expert on user/preventive cold chain & NA & NA & 35.2 & NA & NA & 30.7 & NA & NA & 39.3 \\
\hline \multicolumn{10}{|l|}{ 2. Planning } \\
\hline $\begin{array}{l}\text { 2.1. REC microplan } \\
\text { 2.2. REC microplan (if available), posted on the wall }\end{array}$ & $\begin{array}{l}34.5 \\
20.0\end{array}$ & $\begin{array}{l}45.9 \\
15.8\end{array}$ & $\begin{array}{l}27.6 \\
23.3\end{array}$ & $\begin{array}{l}58.6 \\
27.6\end{array}$ & $\begin{array}{l}73.3 \\
56.7\end{array}$ & $\begin{array}{l}55.8 \\
65.1\end{array}$ & $\begin{array}{l}71.4 \\
42.9\end{array}$ & $\begin{array}{l}72.6 \\
62.6\end{array}$ & $\begin{array}{l}59.6 \\
69.7\end{array}$ \\
\hline 2.3. Outreach/mobile service delivery plan & NA & NA & 29.7 & NA & NA & 57.1 & NA & NA & 60.0 \\
\hline \multicolumn{10}{|l|}{ 3. Logistics and supply } \\
\hline 3.1. Adequate fridge-tag 2 & 75.9 & 71.9 & 72.8 & 82.8 & 78.0 & 78.6 & 75.0 & 72.1 & 82.2 \\
\hline 3.2. Refrigerator spare parts & 44.8 & 23.0 & 16.5 & 41.4 & 89.3 & 32.3 & 39.3 & 40.5 & 39.9 \\
\hline 3.3. Vaccine request and report forms & 79.3 & 65.8 & 47.5 & 82.8 & 89.3 & 65.5 & 82.1 & 78.4 & 71.6 \\
\hline 3.4. EPI vaccine and injection materials stock ledger book & 72.4 & 64.8 & 70.8 & 82.8 & 82.4 & 81.4 & 75.0 & 69.5 & 91.9 \\
\hline 3.5. Inventory documents & 51.7 & 34.7 & 21.9 & 58.6 & 65.6 & 42.4 & 67.9 & 57.4 & 44.1 \\
\hline 3.6. Adequate cold box & NA & NA & 62.5 & NA & NA & 82.1 & NA & NA & 91.6 \\
\hline 3.7. Adequate vaccine carrier with foam pads & NA & NA & 70.2 & NA & NA & 76.1 & NA & NA & 79.9 \\
\hline 3.8. Adequate vaccine storage capacity & NA & NA & 82.2 & NA & NA & 87.9 & NA & NA & 94.0 \\
\hline 3.9. Adequate water/ice packs & NA & NA & 77.8 & NA & NA & 91.2 & NA & NA & 95.1 \\
\hline 3.10. No stock running out in the last 3 months & 41.4 & 52.0 & 71.3 & 62.1 & 78.1 & 78.2 & 39.3 & 58.4 & 67.3 \\
\hline 3.11. Refrigerator temperature monitored twice daily using fridge-tag 2 & 72.4 & 56.6 & 58.1 & 82.8 & 80.5 & 73.9 & 82.1 & 77.9 & 79.7 \\
\hline 3.12. No expired/WM beyond discard point vaccine in refrigerator & 72.4 & 66.3 & 70.8 & 96.3 & 89.6 & 89.4 & 82.1 & 77.9 & 90.1 \\
\hline 3.13. Procedures and actions for vaccines exposed to extreme temperatures & 51.7 & 52.9 & 54.4 & 65.5 & 77.3 & 63.4 & 75.0 & 56.8 & 66.5 \\
\hline \multicolumn{10}{|l|}{ 4. Service delivery } \\
\hline 4.1. Immunization services available & NA & NA & 86.2 & NA & NA & 89.0 & NA & NA & 91.2 \\
\hline 4.2. Regular static immunization services delivered & NA & NA & 76.3 & NA & NA & 84.5 & NA & NA & 84.8 \\
\hline 4.3. Adequate outreach sites & NA & NA & 34.5 & NA & NA & 61.4 & NA & NA & 68.7 \\
\hline 4.4. Catchment area mapped for immunization & NA & NA & 32.9 & NA & NA & 62.2 & NA & NA & 69.4 \\
\hline 4.5. Separate and adequate rooms for immunization services and storing supplies & NA & NA & 43.9 & NA & NA & 53.9 & NA & NA & 58.4 \\
\hline 4.6. All planned outreach sessions were conducted & NA & NA & 27.0 & NA & NA & 52.7 & NA & NA & 64.3 \\
\hline 4.7. Providing health education on immunization & NA & NA & 53.8 & NA & NA & 65.3 & NA & NA & 71.6 \\
\hline 4.8. Immunization services available in all catchment health posts & NA & NA & 76.3 & NA & NA & 86.3 & NA & NA & 86.1 \\
\hline \multicolumn{10}{|l|}{ 5. Documentation } \\
\hline 5.1. Electronic database for monitoring immunization and staff training & 41.4 & 30.1 & 12.5 & 51.7 & 47.9 & 22.2 & 67.9 & 40.0 & 25.8 \\
\hline 5.2. Standard operating procedures on immunization & 24.1 & 30.6 & 23.7 & 69.0 & 42.8 & 43.9 & 67.9 & 57.4 & 56.4 \\
\hline 5.3. Reports received from all catchment health posts and documented & NA & NA & 67.9 & NA & NA & 86.4 & NA & NA & 86.6 \\
\hline 5.4. Tally sheets appropriately documented & NA & NA & 59.3 & NA & NA & 57.9 & NA & NA & 64.8 \\
\hline 5.5. Defaulter tracking list & NA & NA & 36.7 & NA & NA & 36.7 & NA & NA & 83.0 \\
\hline 5.6. Standard case definitions for neonatal tetanus, measles, AFP & NA & NA & 59.3 & NA & NA & 59.3 & NA & NA & 73.3 \\
\hline 5.7. Up-to-date under-one register & NA & NA & 53.6 & NA & NA & 53.4 & NA & NA & 92.5 \\
\hline 5.8. Up-to-date national immunization guidelines & 62.1 & 35.2 & 34.4 & 86.2 & 90.7 & 81.2 & 89.3 & 94.2 & 88.6 \\
\hline
\end{tabular}


Table 3 Percentage scores of process measures at baseline, and at the 6th and 12th month of interventions (Continued)

\begin{tabular}{|c|c|c|c|c|c|c|c|c|c|}
\hline \multirow{2}{*}{$\begin{array}{l}\text { Process measures } \\
6 . \text { Coordination and collaboration }\end{array}$} & \multicolumn{3}{|c|}{ Baseline (\%) } & \multicolumn{3}{|c|}{ After 6 months (\%) } & \multicolumn{3}{|c|}{ After 12 months (\%) } \\
\hline & & & & & & & & & \\
\hline 6.1. Established partners' forum & 14.0 & NA & NA & 20.7 & NA & NA & 26.4 & NA & NA \\
\hline 6.2. Partners' forum meeting conducted as planned & 6.9 & NA & NA & 6.9 & NA & NA & 28.6 & NA & NA \\
\hline 6.3. EPI programme network & 13.8 & 74.0 & NA & 93.1 & 90.2 & NA & 96.4 & 94.2 & NA \\
\hline 6.4. Established technical working group & NA & 30.0 & NA & NA & 55.4 & NA & NA & 55.4 & NA \\
\hline 6.5. Technical working group meeting conducted in the last quarter & NA & 16.8 & NA & NA & 38.7 & NA & NA & 43.2 & NA \\
\hline 6.6. Conducted catchment area meeting in the last quarter & NA & NA & 53.0 & NA & NA & 83.3 & NA & NA & 76.2 \\
\hline 6.7. Inter-facility linkage on immunization services & NA & NA & 83.0 & NA & NA & 80.0 & NA & NA & 92.1 \\
\hline \multicolumn{10}{|l|}{ 7. Monitoring and evaluation } \\
\hline 7.1 Updated EPI monitoring chart posted & 62.1 & 62.8 & 57.2 & 79.3 & 84.9 & 83.3 & 89.3 & 88.0 & 84.1 \\
\hline 7.2. Vaccine logs & NA & NA & 48.3 & NA & NA & 81.9 & NA & NA & 89.4 \\
\hline 7.3. Vaccine and injection materials stock record book & NA & NA & 60.3 & NA & NA & 78.9 & NA & NA & 89.9 \\
\hline 7.4. Conducted internal review meeting on EPI in the last quarter & 27.6 & 35.2 & 48.3 & 44.8 & 64.2 & 64.8 & 64.3 & 71.6 & 68.9 \\
\hline 7.5. SS visit by government or partners in the last quarter & 31.0 & 56.6 & 65.9 & 48.3 & 76.9 & 72.5 & 71.4 & 76.8 & 79.9 \\
\hline 7.6. Data quality check by government or partners in the last quarter & 27.6 & 38.3 & 34.9 & 48.3 & 57.8 & 64.8 & 53.6 & 65.8 & 70.1 \\
\hline 7.7. Timeliness of monthly reports & 55.2 & 55.1 & 59.8 & 79.0 & 80.1 & 61.9 & 82.1 & 94.2 & 74.0 \\
\hline 7.8. Completeness of monthly reports & 65.5 & 61.2 & 58.1 & 86.2 & 89.0 & 81.9 & 89.3 & 94.7 & 81.5 \\
\hline 7.9. Functional performance monitoring team & 75.9 & 60.2 & 41.4 & 86.2 & 84.4 & 74.2 & 92.9 & 90.0 & 74.0 \\
\hline 7.10. Monitored vaccine wastage & 41.4 & 44.9 & NA & 69.0 & 55.5 & NA & 64.3 & 48.0 & NA \\
\hline 7.11. Conducted SS at health posts in the last three months & NA & NA & 48.1 & NA & NA & 43.8 & NA & NA & 51.6 \\
\hline 7.12. Supervised community immunization programme in the last quarter & NA & NA & 46.7 & NA & NA & 64.7 & NA & NA & 67.8 \\
\hline
\end{tabular}

Dist: District health office, Zone: Zonal health department; EPI: Expanded Programme on Immunization; HF: Healthcare facility; IIP: Immunization in Practice; MLM: Mid-level managers; REC: Reaching every community; SS: Supportive supervision; NA: Not applicable

\section{Discussion}

The aim of this study was to implement and evaluate the effectiveness of system-wide CQI interventions to improve national immunization programme performance in Ethiopia. The study was able to provide an understanding of the current status of immunization programme and services at public health sectors, thereby producing a consistent immunization interventions platform to monitor, test, and capture changes. The findings revealed significant improvements in process measures and vaccination coverage after 12 months of strengthening local immunization systems.
The success of an immunization programme requires many parameters to be met, among which is knowledge and skills of immunization service providers and peripheral EPI managers [30]. Our study found a critical shortage of qualified experts to handle current and future immunization programmes at the grassroots level. More than $82 \%$ of zone and district level health departments and offices lack trained experts to lead and manage immunization programmes. The CQI approach mitigated this by providing MLM training to site EPI experts, empowering them to achieve an optimum standard of delivering the immunization programme in

Table 4 Baseline percentage scores of process indicators of national immunization programme and service capacity of the six regions

\begin{tabular}{|c|c|c|c|c|}
\hline & \multirow[t]{2}{*}{ Process indicator } & \multicolumn{3}{|l|}{ Mean score (\%) } \\
\hline & & Zone $(n=29)$ & District $(n=196)$ & Healthcare facility $(n=556)$ \\
\hline \multirow{6}{*}{$\begin{array}{l}\text { National immunization capacity } \\
\text { represented by six regions }\end{array}$} & Human resources & 56.0 & 49.9 & 42.2 \\
\hline & Planning & 20.7 & 31.8 & 40.5 \\
\hline & Logistics and supply & 62.5 & 54.9 & 59.1 \\
\hline & Documentation & 42.5 & 33.3 & 43.7 \\
\hline & Coordination and collaboration & 35.3 & 41.0 & 68.2 \\
\hline & Monitoring and evaluation & 48.3 & 52.2 & 50.3 \\
\hline
\end{tabular}




\section{Process indicators mean value}

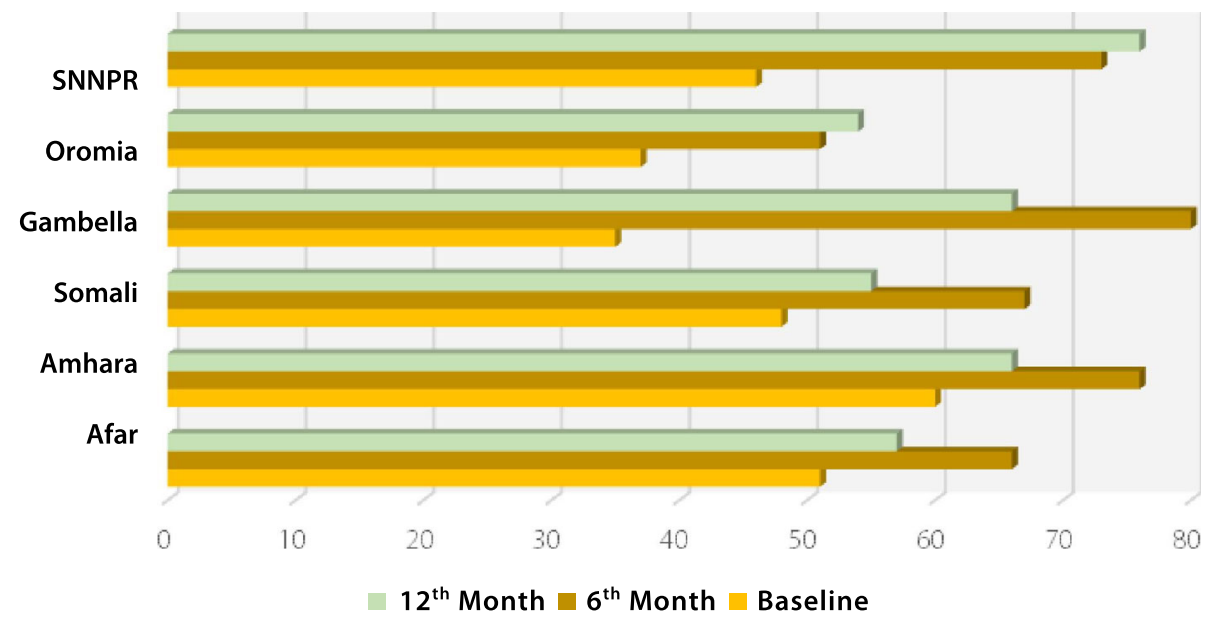

Fig. 3 Capacity to deliver immunization program and services at zonal health departments, district health offices, and healthcare facilities from baseline to the 6th and 12th month of interventions in different regions. SNNPR: Southern nations, nationalities and Peoples' Region

their catchments. A similar approach was followed to channel quality of routine immunization services. Considering the high shortage of healthcare providers to expertly administer immunization services at the healthcare facility and community levels, training on IIP was provided to healthcare workers and health extension workers, enabling them to own and effectively deliver immunization services. Previous studies proved that such training increases knowledge of the frontline staff and boosts overall immunization coverage [31,32].

At a glance, CQI has a proven track record in improving maternal and new-born health interventions in Tanzania, Uganda, and Ghana [33, 34]; human resources for health in Zambia [35]; and prevention of mother-to-child transmission of HIV in South Africa [36]. In Ethiopia, a few studies have generated evidence on the role of CQI in improving diagnostic capacity at healthcare facilities [37] and strengthening district leadership capacity in support of maternal and neonatal health [38]. This study extended the existing evidence on the realistic use of CQI tailored to Ethiopia's local context. Beyond this, there is an increasing tendency to devise mechanisms to assure quality of programmes and services in the overall health system in Ethiopia [39-43].

EPI is still the commonly used programmematic approach to reduce morbidity and mortality among children against the most common vaccine-preventable diseases. With this approach, the global vaccine action plan has targeted to prevent millions of deaths by 2020 through more equitable access to vaccines [30]. In agreement with this global target, Ethiopia, through its comprehensive multi-year plan, aims to vaccinate $90 \%$ of the unmet population by 2020 [16]. This requires an in-depth understanding of EPI programme and service needs on the ground and the fostering of mechanisms to effectively intervene and sustain promising outcomes. This study proved that knowledge on such national immunization plans is limited in many study sites, and national planning documents to refer to and be guided by were missing. The progress towards effectiveness of national immunization programmes needs to empower regional, zonal, district, and facility-level government health sectors to have accountability and share ownership of the outcomes.

Table 5 Percentage scores of outcome measures at baseline, and at the 6th and 12th month of interventions

\begin{tabular}{|c|c|c|c|c|}
\hline \multirow[t]{2}{*}{ Outcome measures } & \multicolumn{4}{|c|}{ Vaccination coverage (\% mean) } \\
\hline & Baseline & At the 6th month & At the 12th month & $P$ value \\
\hline Pentavalent 3 & 63.57 & 80.41 & 79.31 & 0.0001 \\
\hline Measles & 62.46 & 74.48 & 72.81 & 0.009 \\
\hline $\mathrm{BCG}$ & 62.38 & 76.69 & 73.54 & 0.0001 \\
\hline PCV & 65.32 & 79.87 & 81.01 & 0.02 \\
\hline Full vaccination & 56.17 & 88.91 & 74.20 & $0.30^{\text {(not significant) }}$ \\
\hline
\end{tabular}




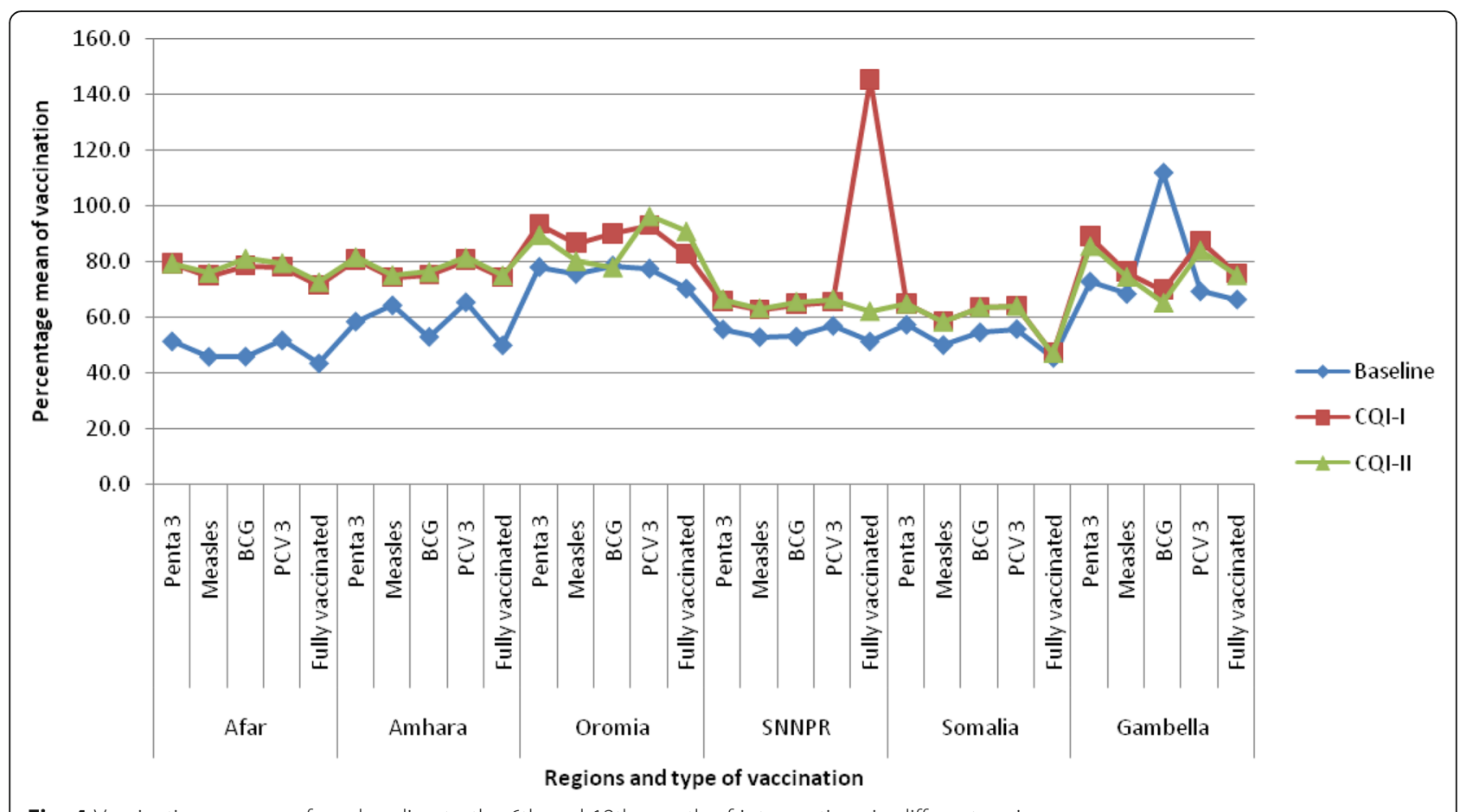

Fig. 4 Vaccination coverage from baseline to the 6th and 12th month of interventions in different regions

With the study interventions, all regions improved their implementation status, and the gap in immunization between developing and emerging regions narrowed. The CQI approach had the advantage of motivating study sites to maximize their effectiveness, which is an important lesson to transfer to other related health programmes. The existing government structure can responsively host and sustain the approach as part of its routine health programme monitoring and evaluation package.

This study had some limitations. A stronger analysis of the immunization trend could have been obtained if the CQI interventions continued beyond 12 months. Six of the nine regional states were included, thus three were untapped, which could limit the contextualization of findings to the national context. The fact that the study sites represented both developing and emerging regions and that there was a large number of sites are strengths of the study.

\section{Conclusions}

The CQI interventions improved process measures and vaccination coverage in Ethiopia through immunization systems strengthening in a PDCA cycle. The study proved that employing data-driven CQI interventions to assess, improve, and continuously follow up immunization programmes is an effective approach to meet national immunization targets. The approach empowered zone, district, and facility-level government health sectors to exercise accountability and share ownership of immunization outcomes. This approach for improvement of immunization capacity suggests that this model could be adapted to other EPI countries. While universal approaches can improve routine immunization, innovative interventions that target local problems and dynamics are also necessary to achieve optimal coverage.

\section{Abbreviations}

BCG: Bacillus Calmette-Guérin; CQl: Continuous quality improvement; EPI: Expanded Program on Immunization; FMoH: Ethiopian Federal Ministry of Health; HF: Healthcare facility; IEHI: Integrated approach to Empower Healthcare facilities on Immunization; IIP: Immunization in practice; MLM: Mid-level managers; NA: Not available; PCV: Pneumococcal Conjugate Vaccine; PDCA: Plan-Do-Check-Act; REC: Reaching every community; SNNPR: Southern nations, nationalities and Peoples' Region; SQUIRE 2.0: Standards for Quality Improvement Reporting Excellence; SS: Supportive supervision; WHO: World Health Organization

\section{Acknowledgments}

The authors acknowledge Dr. Mekdim Enkossa and Ms. Miheret Dana for their technical support as the focal persons of FMoH-Gavi.

\section{Funding}

The project received financial support from Gavi, the Vaccine Alliance through the $\mathrm{FMoH}$ of the Government of Ethiopia.

\section{Availability of data and materials}

The dataset supporting the conclusions of this article is included in the article, while the data collection tools are included as supplementary materials.

\section{Authors' contributions}

TM conceived the study. TM, WA, and DM designed the study. YA, DM, BH, TM, AM, TD, SM, BW, and AA participated in and supervised the data collection. ST, TM, TD, and DZ interpreted the data. TM and ST wrote the first 
draft of the paper. AM, TD, SM, YA, and DZ reviewed the first draft of the paper. All authors participated in the review, feedback, and approval of the paper for publication.

\section{Ethics approval and consent to participate}

The study protocol has been approved by the Internal Scientific and Ethical Review Committee of the Ethiopian Public Health Association. Permission to undertake the study was obtained from the $\mathrm{FMoH}$ and the Afar, Amhara, Gambella, Oromia, SNNPR, and Somali regional health bureaus. Privacies of staff involved were sufficiently protected.

\section{Consent for publication}

The study does not include details, images, or videos relating to individual participants, thus consent for publication was not required.

\section{Competing interests}

The authors each individually and collectively declare that there are no conflicts of interest.

\section{Author details \\ ${ }^{1}$ Ethiopian Public Health Association, P.O. Box 7117, Addis Ababa, Ethiopia. ${ }^{2}$ Ethiopian Medical Association, P.O. Box 2179, Addis Ababa, Ethiopia. ${ }^{3}$ Ethiopian Pediatrics Society, P.O. Box 14205, Addis Ababa, Ethiopia. ${ }^{4}$ Department of Pediatrics and Child Health, School of Medicine, College of Health Sciences, Addis Ababa University, P.O. Box 9086, Addis Ababa, Ethiopia. ${ }^{5}$ Federal Ministry of Health, Government of Ethiopia, P.O. Box 1234 Addis Ababa, Ethiopia. ${ }^{6}$ Center for Innovative Drug Development and Therapeutic Trials for Africa (CDT-Africa), College of Health Sciences, Addis Ababa University, P.O. Box 9086, Addis Ababa, Ethiopia.}

\section{Received: 9 March 2018 Accepted: 13 November 2018} Published online: 30 November 2018

\section{References}

1. Bar-Zeev N, Tate JE, Pecenka C, Chikafa J, Mvula H, Wachepa R, et al. Costeffectiveness of monovalent rotavirus vaccination of infants in Malawi: a post-introduction analysis using individual patient-level costing data. Clin Infect Dis. 2016;62(2):S220-8.

2. Fast SM, González MC, Markuzon N. Cost-effective control of infectious disease outbreaks accounting for societal reaction. PLoS One. 2015;10(8): e0136059.

3. Machingaidze S, Wiysonge CS, Hussey GD. Strengthening the expanded programme on immunization in Africa: looking beyond 2015. PLoS Med. 2013;10(3):e1001405

4. Johansson KA, Memirie ST, Pecenka C, Jamison DT, Verguet S. Health gains and financial protection from pneumococcal vaccination and pneumonia treatment in Ethiopia: results from an extended cost-effectiveness analysis. PLoS One. 2015;10(12):e0142691.

5. Bloom DE, Black S, Rappuoli R. Emerging infectious diseases: a proactive approach. Proc Natl Acad Sci U S A. 2017;114(16):4055-9.

6. Røttingen JA, Gouglas D, Feinberg M, Plotkin S, Raghavan KV, Witty A, et al. New vaccines against epidemic infectious diseases. N Engl J Med. 2017; 376(7):610-3.

7. Jansen KU, Knirsch C, Anderson AS. The role of vaccines in preventing bacterial antimicrobial resistance. Nat Med. 2018;24(1):10-9.

8. Restrepo-Méndez MC, Barros AJ, Wong KL, Johnson HL, Pariyo G, França GV, et al. Inequalities in full immunization coverage: trends in low- and middleincome countries. Bull World Health Organ. 2016;94(11):794-805.

9. Nelson KN, Wallace AS, Sodha SV, Daniels D, Dietz V. Assessing strategies for increasing urban routine immunization coverage of childhood vaccines in low and middle-income countries: a systematic review of peer-reviewed literature. Vaccine. 2016;34(46):5495-503.

10. Ashok A, Brison M, LeTallec Y. Improving cold chain systems: challenges and solutions. Vaccine. 2017;5(17):2217-23.

11. Ethiopian Federal Ministry of Health $(\mathrm{FMOH})$. Ethiopia Routine Immunization Improvement Plan. Addis Ababa, Ethiopia: FMoH; 2013.

12. World Health Organization Regional Office for Africa. WHO country cooperation strategy: 2012-2015 Ethiopia. Brazzaville. In: Congo: WHO; 2013.

13. Gebremariam MB. Perspectives on optimization of vaccination and immunization of Ethiopian children/women: what should and can we further do? Why and how? Ethiop Med J. 2012;50(2):167-84.
14. Travassos MA, Beyene B, Adam Z, Campbell JD, Mulholland N, Diarra SS, et al. Immunization coverage surveys and linked biomarker sero-surveys in three regions in Ethiopia. PLoS One. 2016;11(3):e0149970.

15. LaFond A, Kanagat N, Steinglass R, Fields R, Sequeira J, Mookherii S. Drivers of routine immunization coverage improvement in Africa: findings from district-level case studies. Health Policy Plan. 2015;30(3):298-308.

16. Ethiopian Federal Ministry of Health (FMoH). Ethiopian national expanded program on immunization: comprehensive multi-year plan 2016-2020. Addis Ababa. In: Ethiopia: FMoH; 2015.

17. Lorch JA, Pollak VE. Continuous quality improvement in daily clinical practice: a proof of concept study. PLoS One. 2014;9(5):e97066.

18. Kronick SL, Kurz MC, Lin S, Edelson DP, Berg RA, Billi JE, et al. Part 4: systems of care and continuous quality improvement: 2015 American Heart Association guidelines update for cardiopulmonary resuscitation and emergency cardiovascular care. Circulation. 2015;132:S397-413.

19. Hempel S, Rubenstein LV, Shanman RM, Foy R, Golder S, Danz M, et al. Identifying quality improvement intervention publications - a comparison of electronic search strategies. Implement Sci. 2011;6:85.

20. Leebov W, Ersoz CJ. The health care manager's guide to continuous quality improvement. Lincoln. In: NE: iUniverse; 2003.

21. Nadeem E, Olin SS, Hill LC, Hoagwood KE, Horwitz SM. Understanding the components of quality improvement collaboratives: a systematic literature review. Milbank Q. 2013;91(2):354-94.

22. National Learning Consortium. Continuous quality improvement (CQI) strategies to optimize your practice. Washington, US: Health Information Technology Research Center; 2013.

23. Wondwossen L, Gallagher K, Braka F, Karengera T. Advances in the control of vaccine preventable diseases in Ethiopia. Pan Afr Med J. 2017;27(2):1.

24. Habib M, Yusuf AM. The Ethiopian federal system: the formative stage. Friedrich-Ebert-Stiftung: Addis Ababa, Ethiopia; 2011.

25. Gebre-Egziabhere T. Emerging regions in Ethiopia: are they catching up with the rest of Ethiopia? East Afr Soc Sci Res Rev. 2018;34(1).

26. Ethiopian Public Health Institute (EPHI). Ethiopia service provision assessment plus-census 2014. Addis Ababa, Ethiopia: EPHI; 2014.

27. World Health Organization (WHO). Modules for immunization training for global mid-level managers (MLM). In: Geneva: Switzerland: WHO; 2008.

28. World Health Organization (WHO). Immunization in practice (IIP): a practical guide for health staff. Geneva. In: Switzerland: WHO; 2015.

29. Ogrinc G, Davies L, Goodman D, Batalden P, Davidoff F, Stevens DSQUIRE. 2. 0 (standards for QUality improvement reporting excellence): revised publication guidelines from a detailed consensus process. BMJ Qual Saf. 2016;25(12):986-92.

30. World Health Organization (WHO). Global vaccine action plan. Geneva: Switzerland: WHO. 2011-2020:2013.

31. Brown AN, Prosser W, Zwinkels D. Who is preparing the next generation of immunization supply chain professionals? Vaccine. 2017;35(17):2229-32.

32. Uskun E, Uskun SB, Uysalgenc M, Yagiz M. Effectiveness of a training intervention on immunization to increase knowledge of primary healthcare workers and vaccination coverage rates. Public Health. 2008;122(9):949-58.

33. Graft Johnson J d, Vesel i, Rosen HE. Cross-sectional observational assessment of quality of newborn care immediately after birth in health facilities across six sub-Saharan African countries. BMJ Open. 2017;7(3): e014680.

34. Srofenyoh E, Ivester T, Engmann C, Olufolabi A, Bookman L, Owen M. Advancing obstetric and neonatal care in a regional hospital in Ghana via continuous quality improvement. Int J Gynaecol Obstet. 2012;116(1):17-21.

35. Bazant E, Sarkar S, Banda J, Kanjipite W, Reinhardt S, Shasulwe H, et al. Effects of a performance and quality improvement intervention on the work environment in HIV-related care: a quasi-experimental evaluation in Zambia. Hum Resour Health. 2014;12:73.

36. Doherty T, Chopra M, Nsibande D, Mngoma D. Improving the coverage of the PMTCT programme through a participatory quality improvement intervention in South Africa. BMC Public Health. 2009;9:406.

37. Marinucci F, Manyazewal T, Paterniti AD, Medina-Moreno S, Wattleworth M, Hagembe J, et al. Impact of horizontal approach in vertical program: continuous quality improvement of malaria and tuberculosis diagnostic services at primary-level medical laboratories in the context of HIV care and treatment program in Ethiopia. Am J Trop Med Hyg. 2013;88(3):547-51.

38. Stover KE, Tesfaye S, Frew AH, Mohammed H, Barry D, Alamineh L, et al. Building district-level capacity for continuous improvement in maternal and newborn health. J Midwifery Women's Health. 2014;59(1):S91-S100. 
39. Miller NP, Amouzou A, Hazel E, Legesse H, Degefie T, Tafesse M, et al. Assessment of the impact of quality improvement interventions on the quality of sick child care provided by health extension Workers in Ethiopia. J Glob Health. 2016;6(2):020404.

40. Manyazewal T, Paterniti AD, Redfield RR, Marinucci F. Role of secondary level laboratories in strengthening quality at primary level health facilities' laboratories: an innovative approach to ensure accurate HIV, tuberculosis, and malaria test results in resource-limited settings. Diagn Microbiol Infect Dis. 2013;75(1):55-9.

41. Hiwotu TM, Ayana G, Mulugeta A, Kassa GB, Kebede Y, Fonjungo PN, et al. Laboratory system strengthening and quality improvement in Ethiopia. Afr J Lab Med. 2014;3(2):228.

42. Kebede $Y$, Fonjungo PN, Tibesso G, Shrivastava R, Nkengasong JN, Kenyon T, et al. Improved specimen-referral system and increased access to quality laboratory services in Ethiopia: the role of the public-private partnership. Infect Dis. 2016;213(2):S59-64.

43. Azazh A, Brown LD, Ayele RA, Teklu S, W/Tsadik a, Tefera M, et al. Enhancing emergency medicine initiatives with a quality improvement program: lessons learned in the emergency department of Tikur Anbessa Hospital, Addis Ababa Ethiopia. Ethiop Med J. 2014:2:37-44.

Ready to submit your research? Choose BMC and benefit from:

- fast, convenient online submission

- thorough peer review by experienced researchers in your field

- rapid publication on acceptance

- support for research data, including large and complex data types

- gold Open Access which fosters wider collaboration and increased citations

- maximum visibility for your research: over $100 \mathrm{M}$ website views per year

At $\mathrm{BMC}$, research is always in progress.

Learn more biomedcentral.com/submissions 